\title{
The Green Design Concept in New Product Development
}

\author{
FEI HE ${ }^{1, a}$ \\ ${ }^{1}$ School of Art And Design ,Jingdezhen Ceramic Institute,Jiangxi,China \\ ah_fei1225@126.com
}

\begin{abstract}
Keywords: new product development; green design; production process
Abstract. Currently, green design is discussed just as a concept in industrial design area. With the spread of green knowledge, the consumption concepts such as reasonable and rational consumption and emphasis on ecological effect in consumption have gradually affected people's consumption behaviors. More and more consumers believe that green consumption is lofty and rational and green design can strengthen the public environmental awareness and sense of social responsibility effectively. Therefore, it is very necessary to study by linking the method and theory of green design with new product development. That is to say, the whole process of new product development should be explored from prospective of green design and be guided by the theory of green design. From the point of view of green design, this paper combines the economic efficiency of the product with the environmental protection property of the product, thus providing a new idea for the development of enterprises.
\end{abstract}

\section{Introduction}

In the long history of human design, while creating the modern way of life and living environment for human beings, the industrial design has also accelerated the consumption of resources and energy and caused great damage to the ecological balance of the earth. The over commercialization of industrial design makes design the major medium to encourage the immoderate consumption of people. Just under such background, designers have to rethink the responsibilities and roles of industrial designers. At the same time, American design theorist Victor Babarnack published a controversy monograph Design for the Real World. He stressed that the design should take into serious consideration the use of limited resources on the earth and contribute to the protection of the environment. There were only a few people can understand his view. Later, with the continuous development of science and technology and the improvement of human material and spiritual civilization, human beings realize that the living environment is worsening, and the available resources are depleting. All these problems have a direct impact on the reproduction of human civilization, so the strategy of sustainable development is put forward . In late 1980s, the wave of "green consumption" first gained steam in the United States, and then swept the world. Gradually, green design has received more and more attention and recognition from people.

As the competition among enterprises in modern market is becoming increasingly fierce, to maintain the competitive edge in the market, enterprises have to continuously innovate and develop new products. The development of new products has a great significance for the survival and development of enterprises. Driven by the wave of green consumption, the governments of many countries have actively guided the consumers to extend their vision to the natural ecological environment, and advocated green consumption concepts and patterns in the whole society. A foreign consumption survey shows that over $75 \%$ of Americans claim that the green image of enterprises and products will directly influence their buying behaviors. There are nearly half of consumers considering environmental issue when buying and using the product on the European market, and consumers in Asia, Japan, South Korea and Hong Kong are also keen to green products. In China, with the improvement of people's consumption demand, they not only focus on the demand of quantity, but also begin to pay attention to the impact of the products on the environment, so they tend to choose green products. Therefore, if we combine the green design concepts and methods with the development of new products and use it to guide the whole process of developing new products, it is bound to develop the green products which 
are more in line with the consumers' demands and more environmentally friendly, thus providing a new way for the manufacturing enterprises.

\section{Green design}

The basic idea of green design. The environmental factors and pollution prevention measures should be incorporated into the product design in the design stage. The environmental performance should be taken as the design goal and starting point of the product, so as to reduce the impact on the environment to the minimum.

The principle of green design. The principle of green design is the acknowledged " $3 \mathrm{R}$ "principle, namely, reduce, reuse and recycle. We should not only reduce the consumption of materials and energy and the emission of harmful substance, but also make the products or components easy to sort, recycle or reuse.

\section{The related contents of new product development}

The so-called new product means that the product enjoys advancement and originality in one or more aspects such as product performance, structure, material, usage or technology performance. The advancement of a new product is mainly reflected in the application of new principle, structure, technology and material in its design. In terms of developing new products, the first thing is to determine the design task and identify design content. Then we should make the design plan according to the design task. After making the design plan, we should carry out the preliminary design survey and sort the information. According to the data collected from market survey, we make analysis and draw the conclusion, and then we create the design scheme. Besides, the scheme should be evaluated form the aspects such as function, structure, morphology, ergonomics and environment, and the scheme with the best evaluations can be the final solution. Then we should continue the manufacturing of the prototype model, after that it should be transferred to the engineering department or mold factory for product manufacturing. Necessarily, the package and display design of the product should be carried out before putting it into the market, and then we should make the product VI manual, put it into the market and receive market feedback.

\section{The application of green design concept in new product development}

The application of green design concept in the stage of market research. As to enterprises, if they want to grasp the consumers' potential demand of products, they must know well the consumers' appeal through the information from various research channels. In the process of research, many research institutes find that consumers hope to buy the product of many functions and utility with less money. The decrease of usage charge mainly depends on the reduction of energy consumption. That is to say, how to enable the product to save energy and reduce consumption. In the stage of market research, after understanding consumers' appeal, the product R\&D department of enterprises should manufacture the products meeting the consumers' demand according to their appeal. Now, there are three types of washing machines with different washing principles: pulsator washing machine, roller washing machine and inclined-barrel washing machine. These three types of washing machine were put into the market in different period, with different displacements. The displacement of the pulsator washing machine which was brought to market in 1970s is the largest, because it washes clothes relying on filling the inner-barrel with water. Next is the roller washing machine. Its washing principle is based on the method of striking clothes with a wooden club, and it washes the clothes relying on spray system. While, the inclined-barrel washing machine consumes the least water of the three. Because the inner-barrel has a 15 degree angle of inclination, the injected water is less than the above two. It can be seen that the manufacturer of washing machine is paying increasing attention to the consumers' demand, and adhering to the concept of power and water saving to the best of their ability. 
At the same time, many consumers or environmentalists hope that after the end of product life cycle, the components or raw materials used for manufacturing product can be recycled, which is the use of renewable resource in product design and manufacturing. In 1986, the Fuji Film launched a new product --- unifunctional camera, which achieved great success immediately after it was displayed on Japanese local shelf. It is constructed by a roll of film embedded in the carton and a cheap plastic camera lens. The camera is low in price and easy to purchase, and after taking the photos, the whole camera has to be sent for processing, which is a disposable camera. After achieving success in local market, the unifunctional camera of Fuji Film was launched in American market in 1987, but it did not succeed. In addition to doubting the reliability and quality of the product, more importantly, the consumers believe that the disposable camera is a waste of resources. In the stage of product research, Fuji Film didn't take environmental awareness into consideration, namely, the impact of the use of unifunctional camera on environment. Besides, they didn't consider whether consumers or environmentalists would have resistance. Therefore, though it has achieved success in Japan, it does not win the American market. When American Eastman Kodak Company launched unifunctional camera in the local market, it summed up Fuji Film's reason of failure. Therefore, first of all Kodak Company made a relevant survey to environmentalists and shutterbugs about the environmental disruption of disposable camera. According to the survey result, Kodak Company eased the consumers' and environmentalists' misgiving through recycling plan.

It can be seen that the R\&D department of enterprises should apply the green design concept into the process of product survey at the beginning of developing new product. It collects information about green and environmental protection from patent and news materials in the form of Internet survey and field visit, and then guides the following new product development obtained in the early survey.

The application of green design method in the stage of product design. Modular design is one of the methods of green design. In brief, the so-called modular design is to combine some of the elements of product and constitute a subsystem with specific function. And then the subsystem is combined with the elements of other products as a general modular, constituting a new system and producing serial products with different or same functions and different performances. On the one hand, it can shorten the cycle of product development and manufacturing, improve product quality and respond to market changes quickly; on the other hand, it can also reduce or eliminate the adverse impact on environment, facilitate the reuse, upgrade, maintenance as well as the disassembly and recycle after the product is discarded. The method of modular design is widely used in new product development. Fox example, in 2014, the Slovenia designer Janez Mesaric applied the modular design to the seat design, and designed a modular plastic chair, which was named after the capital of Slovenia, Ljubljana. The chair is composed of two simple modular units, and through the unit combination with different numbers, users can assemble the chair of different sizes, thus meeting the demand of different spaces. Besides, the chair is made of reinforced polypropylene plastics, which can be recycled absolutely. Such material will absorb carbon dioxide when it is produced, which is not only environmentally friendly but also light in quality. In addition to the modular furniture, there are also modular tents. The honey-combed modular tents have been produced in batch. Inspired by the beehive, the designer B-AND-BEE puts up a camping tent with the stacked hexagonal boxes. Each tent is equipped with mental framework and dual sealed timber with waterproof fabric. The interior of the tent provides the location of luggage, and the large bed in the tent can be used as lounge seating. While after removing the fabric plate, the tent can be functioned as the comfortable seats for watching the concert. Both of the two products have achieved tremendous success after entering the market.

The application of principle of disassembly in the new product structure design. The principle of disassembly is one of the $3 \mathrm{R}$ principles of green design. It requires taking the disassembly as an aim of structure design in the primary stage of production design, so that the connective structure of the product is easy to disassemble and the abandoned products can be recycled effectively. In this way, it can achieve the purpose of conserving resources and protecting environment. 
The disassembly of the product is an important condition for product recycling, which directly affects the product recycling. The disassembling advantage of products is also reflected in the maintenance of the product. In order to achieve the product maintenance, the disassembly of products must be considered in the design stage of disassembly. The parts which are easy to break down should be easily dismantled, and reasonable structure design can improve the service life of the products. Within the structure of mobile phone, the threaded connection is difficult to assemble and disassemble, but if we change it with buckle connection, it will be much convenient. In the disassembling design of products, through disassembling and reassembling, the products can adapt to the growth change of human body, thus achieving the purpose of changing from single function to multiple functions and extending the service life of the products, such as the child's growth desk, chairs and other products, which serves the demand of children of different ages through the disassembly and assembly of the products.

The application of principle of recyclability in the new product packaging. For the current manufacturing enterprises, it seems that that packaging of new product must be glamorous to attract consumers, and only in this way can people be easier to accept. However, once they begin using the product, the outer package of the product will be discarded by them conveniently. Such pollution from packaging can be seen everywhere, so various bacteria emitted by the solid waste of package are bred, which causes serious harm to the people's health. Thus it can be seen that both the manufacturers and consumers should consider from the perspective of environmental protection and recycling, and make the whole life cycle from the packaging material selection, manufacturing, using and discarding of raw materials comply with the requirements of environmental protection. At the same time, the selected material should also have such characteristics as recycling, easy degradation and regeneration. Now many packages of new products have abandoned the luxury decorations and materials which are difficult to recycle, while they select the recycling and easily degradable materials, such as the corrugated paper. It is a common material used as the outer package of many household appliances, food and digital appliances, whose advantages are low cost, light weight, easy processing and high intensity. Besides, over $80 \%$ of the corrugated paper can be reproduced through recycling. Since the establishment in 1980s, Japanese brand Muji has advocated a simple way of life by thoroughly simplifying the production process of commodity. The packaging materials use a lot of unbleached pale yellow paper, so that customers can see the products directly through the packaging. Such a simple and direct way enables consumers to understand at a glance, narrows the distance between the goods and customers and reduces the environmental pollution. Besides, the paper materials are also easy to recycle.

\section{Conclusion}

Green design mirrors people's reflection on the environmental and ecological disruption caused by modern technology culture, and also reflects the return of designer's morality and social responsibility. In the process of developing new products, Chinese enterprises tend to choose the production mode of resource consumption, which leads to the consumption of resource and energy, and aggravates the environmental pollution. As a result, the whole environment which mankind live by will be affected. Therefore, from the perspective of green design concept, this paper combines the economic efficiency of the product with the environmental protection property of the product, thus providing a new idea for the development of enterprises.

\section{References}

[1] Guangfu Liu, Zhifeng Liu: Green Design and Green Manufacturing, Beijing: Mechanical Industry Press, 2000

[2] Changjie Chen: Green Packaging Technology and Its Typical Cases [M]. Beijing: Chemical Industry Press, 2008 